\title{
MORFOLOGÍA PALINOLÓGICA Y VIABILIDAD EN ESPECIES \\ DE CANNA L. (CANNACEAE - ZingIBERALES) E HÍBRIDOS RELACIONADOS
}

\author{
Pollen morphology and Viability in species of CanNa L. \\ (CANNACEAE - ZINGIBERALES) AND RELATED HYBRIDS
}

\author{
María de las Mercedes Ciciarelli ${ }^{1 *}$ (D) y Lilian M. Passarelli1,2 (D)
}

1. Laboratorio de Estudios de Anatomía Vegetal Evolutiva y Sistemática (LEAVES), Facultad de Ciencias Naturales y Museo, Universidad Nacional de La Plata, $64 \mathrm{~N}^{\circ} 3$ entre 120 y diagonal 113 , La Plata. Argentina. Cátedra de Introducción a la Botánica.

2. Cátedra de Palinología, FCNyMUniversidad Nacional de La Plata, Argentina.

*mercedes.ciciarelli@yahoo.com.ar, mercedes.ciciar@gmail.com

Citar este artículo

CICIARELLI, M. de las M. y L. M. PASSARELLI. 2020. Morfología palinológica y viabilidad en especies de Canna L. (CannaceaeZingiberales) e híbridos relacionados. Bol. Soc. Argent. Bot. 55: 231-241.

DOI: https://doi. org/10.31055/1851.2372.v55. n2.23738

Recibido: 18 Marzo 2019 Aceptado: 20 Abril 2020

Publicado: 30 Junio 2020

Editor: Gonzalo Márquez (D)

ISSN versión impresa 0373-580X

ISSN versión on-line 1851-2372

\section{SUMMARY}

Background and aims: Cultivars of Canna resulted of intensive hybridization on five parental species: C. flaccida Salsb., C. glauca L., C. indica L., C. iridiflora Ruiz et Pav. and C. warscewiczii A. Dietr. Here we study for the first time the palynological morphology and pollen viability of three hybrids belonging to the nothospecies $C$. $x$ generalis and three parental species, C.glauca, C. indica and C. warscewiczii, that grow in Argentina. The objective of this work is to contribute with information about hybridization and artificial evolution of the genus Canna through a study of palynological morphology and pollen viability.

M\&M: Pollen grains of live flowers were observed with an optical microscopy following Wodehouse technique. As Canna pollen grains do not resist Erdtman acetolysis, the observation of sporoderm and spines was performed with a scanning electronic microscope, whereas pollen viability was studied through MTT technique, (Rodriguez-Riano \& Dafni 2000).

Results: In wild species the shape and size of pollen grains are regular as well as the size, morphology, distribution, and density of spines. In the hybrids the mentioned traits result irregular and spines density is 2-3 times higher.

Conclusions: Pollen viability results were correlated with the presence and absence of seeds.

\section{KEY WORDS}

Canna, C. x generalis, Cannaceae, domestication, morphology, pollen grains, spines, viability.

\section{RESUMEN}

Introducción y objetivos: Los cultivares de Canna resultaron de la hibridación intensiva de cinco especies americanas diploides: C. flaccida Salsb., C. glauca L., C. indica L, C. iridiflora Ruiz et Pav. y C. warscewiczii A. Dietr. Se estudia por primera vez la morfología palinológica y la viabilidad del polen de tres híbridos triploides pertenecientes a la notoespecie $C . x$ generalis y de tres especies parentales: C. glauca, C. indica y C. warscewizii, que crecen en Argentina. El objetivo es aportar información sobre la hibridización y la evolución artificial del género Canna mediante un estudio de la morfología palinológica y la viabilidad del polen.

M\&M: Los granos de polen de flores frescas se observaron con microscopio óptico siguiendo la técnica de Wodehouse. La observación de la esporodermis y de las espinas se realizó con un microscopio electrónico de barrido, en tanto que la viabilidad del polen se estudió mediante la técnica de MTT (Rodriguez-Riano \& Dafni, 2000).

Resultados: Los caracteres morfológicos observados indicaron diferencias significativas. En las especies silvestres, la forma y el tamaño de los granos es regular al igual que el tamaño, morfología, distribución y densidad de las espinas. En los híbridos, los caracteres mencionados resultan irregulares, con importantes diferencias en el tamaño y con una densidad de espinas 2-3 veces mayor que la del polen perteneciente a las especies parentales.

Conclusiones: Los resultados de la viabilidad del polen se correlacionan con la presencia y la ausencia de semillas.

\section{Palabras clave}

Canna, C x generalis, Cannaceae, domesticación, espinas. granos de polen, morfología, viabilidad. 


\section{INTRODUCCIÓN}

El género Canna L. ha sido objeto de domesticación por el hombre con fines alimentarios y ornamentales. Las especies nativas de Sud y Centroamérica evolucionaron en sus hábitats en forma natural y también por acción de los pueblos originarios, quienes eligieron y cultivaron aquellas plantas con rizomas más desarrollados y palatables.

Según Khoshoo \& Mukherjee (1970), las especies parentales de Canna contienen numerosos genes múltiples que juntos forman un sistema estable. Cuando esos genes fueron puestos en contacto por los productores, las barreras ecogeográficas se rompieron y la amplia variabilidad se liberó posibilitando una rápida evolución de las variedades de jardín. Los caracteres que fueron cambiando debido a las sucesivas cruzas son el contorno, tamaño, textura y color de hojas y flores. Las piezas florales más vistosas son los estaminodios: erguidos, estrechos y concolores en las especies nativas, y reflejos, anchos con márgenes rizados y una amplia variación de colores en los cultivares. De acuerdo con este autor, el color es un carácter controlado por diferentes genes intensificadores, inhibidores y letales.

Las formas ornamentales de Canna que crecen en los jardines, fueron el resultado de la hibridación intensiva de cinco especies americanas, diploides: $C$. flaccida Salsb., C. glauca L., C. indica L., C. iridiflora Ruiz et Pav. y $C$. warscewiczii A. Dietr., introducidas en Europa en 1848, (Khoshoo \& Mukherjee, 1970). A mediados del siglo XIX se buscó obtener mediante las sucesivas cruzas plantas con flores más grandes y una mayor adaptabilidad al clima frío de Europa, lo que produjo cambios en las inflorescencias, período de floración, durabilidad y tamaño floral. En 1848, Anné obtuvo las primeras achiras híbridas conocidas por la cruza entre $C$. indica y $C$. glauca. Más tarde, Ehemann en 1863 cruzó a $C$. iridiflora y $C$. warsewiczii y si bien las plantas obtenidas eran más atractivas que las especies parentales, las flores eran aún pequeñas y poco vistosas. El cruzamiento y retrocruzamiento efectuado entre los dos grupos de plantas mencionadas dio lugar a un conjunto de cultivares que en 1868 se llevaron al mercado con diferentes nombres, "cannas francesas enanas", "crozy", o "gladiolus" y más tarde Bailey $(1923,1930,1951)$ las llamó colectivamente C. $x$ generalis. Este grupo contenía plantas híbridas diploides y triploides con flores más grandes, estaminodios más anchos, reflejos, de márgenes rizados y gran variación en el color. Las posteriores cruzas se efectuaron entre las variedades de $C x$ generalis y $C$. flaccida, ya que esta última es la única especie parental con flores de estaminodios amarillos, anchos y reflejos. El resultado de las cruzas dio lugar a un nuevo grupo de plantas las llamadas "cannas italianas", "Iris", "orquídeas" o "cannas de flores gigantes". Este último grupo de plantas más vigorosas y con mayor tamaño y diámetro floral se denominaron colectivamente $C$. $x$ orchiodes (Bailey, 1951). Si bien ambos grupos de cultivares se han separado en base a la presencia de pétalos erectos en las flores del primero y de pétalos reflejos en el segundo, algunos autores consideran que tales diferencias son poco notables y menos precisas a medida que se sucedieron las cruzas. La tendencia seguida actualmente por el Código Internacional de Nomenclatura de Plantas Cultivadas (Brickell et al., 2009) es que todos los cultivares actuales se agrupan en la notoespecie Canna x generalis L. H. Bailey y dentro de ella se clasifican a las diferentes variedades en "grupos de cultivares", considerando a C. $x$ orchioides un sinónimo de C.x generalis.

De acuerdo a nuestras observaciones la notoespecie C. $x$ generalis comprende plantas de tamaño mediano, de 1,50 a $2 \mathrm{~m}$ de altura aproximadamente con inflorescencias reducidas, flores grandes y próximas de diferentes colores, rosa claro, rosa intenso, salmón, rojo brillante, rojo oscuro, amarillo, amarillo moteado de naranja o rojizo a pardo, con pétalos erectos o reflejos y estaminodios anchos reflejos con márgenes enteros, ondulados o crespos. Las hojas tienen láminas de contornos lanceolados u oblongos, de color verde claro con venas secundarias de color blanco o verde, o también verde con márgenes rojizos, u hojas ovado lanceoladas a oblongas de color púrpura o verde $\mathrm{y}$ púrpura, concolores o discolores con venas secundarias verdes, blancas o púrpuras.

Aquí seguimos esta propuesta taxonómica y seleccionamos tres variedades: C. $x$ generalis "Black Knight" (antes C. $x$ orchioides) con hojas de color pardo a púrpura y flores rojo oscuro, C. $x$ generalis 'Orange King Humbert', de hojas verdes concolores y flores con estaminodios amarillos moteados o pintados de color anaranjado, y C. x generalis "Wyoming", con hojas de color pardo a púrpura y flores anaranjadas con líneas rojas. (Fig. 1 E-G).

En relación a la morfología polínica estudios recientes del género (Ciciarelli 2007, Ciciarelli \& Rolleri 2008, Ciciarelli et al. 2010a), han observado que la forma, tamaño (largo $\times$ ancho) y densidad de 


\section{M. Ciciarelli y L. M. Passarelli - Palinología y viabilidad en Canna e híbridos relacionados}

espinas, son caracteres diagnósticos en las siguientes especies argentinas y neotropicales: $C$. ascendens Ciciar. C. compacta Rosc., C. coccinea Mill., C. fuchsina Ciciar., C. paniculata Ruiz et Pav. y $C$. variegatifolia Ciciar.

Hasta el momento el primer autor en mencionar e ilustrar granos de polen de taxones híbridos fue Tanaka (2001) quien estudió los granos de polen de $C$. discolor Lindl. un taxón triploide y estéril. Los granos presentan una distribución menos regular de las espinas y una mayor densidad y tamaño de las mismas.

Aquí se estudiaron por primera vez comparativamente los granos de polen de 3 híbridos ornamentales triploides (Mukherjee et al, 1970, Tokugawa et al. 1924) con el polen de 3 especies parentales, diploides, (Tanaka, 2001) C. glauca, C. indica y $C$. warscewizii, que crecen en Argentina. El objetivo es aportar información sobre la hibridización y la evolución artificial del género Canna mediante un estudio de la morfología palinológica y la viabilidad del polen.

\section{Materiales y Métodos}

Los estudios se efectuaron con material fresco, las especies e híbridos se recolectaron en zonas de humedales bonaerenses prístinas y suburbanas. Los granos de polen no resisten la acetólisis de Erdtman (1960) por ello se siguió la técnica de tinción de Wodehouse (1935). Para la observación con MEB, los granos de polen se colocaron sobre cinta adhesiva doble faz, fueron metalizados con oro paladio y examinados con un microscopio electrónico de Barrido perteneciente al CINDECA-CONICET-UNLP. Las fotografías obtenidas aportaron a la escultura del esporodermo y a la densidad de las espinas en un campo de $400 \mu \mathrm{m}^{2}$. La viabilidad del polen se estudió en todas las especies e híbridos siguiendo la técnica MTT (Rodriguez-Riano \& Dafni, 2000).

\section{Material de referencia}

Canna glauca. ARGENTINA. Prov. Buenos Aires. Dpto. Ensenada, Los Talas, Ciciarelli, 80,16-12-2014 (LP).

Canna indica. ARGENTINA. Prov. Buenos Aires. Dpto. La Plata. City Bell, Arroyo Rodriguez, Ciciarelli, 90, 16-12-2014 (LP).

Canna $x$ generalis "Orange King Humbert". ARGENTINA. Prov. Buenos Aires. Dpto. La Plata. City Bell. Cno. Gral. Belgrano y 488 Ciciarelli, 100,1012-2014 (LP).

Canna x generalis “Wyoming” ARGENTINA. Prov. Buenos Aires. Dpto. La Plata. City Bell. Calle

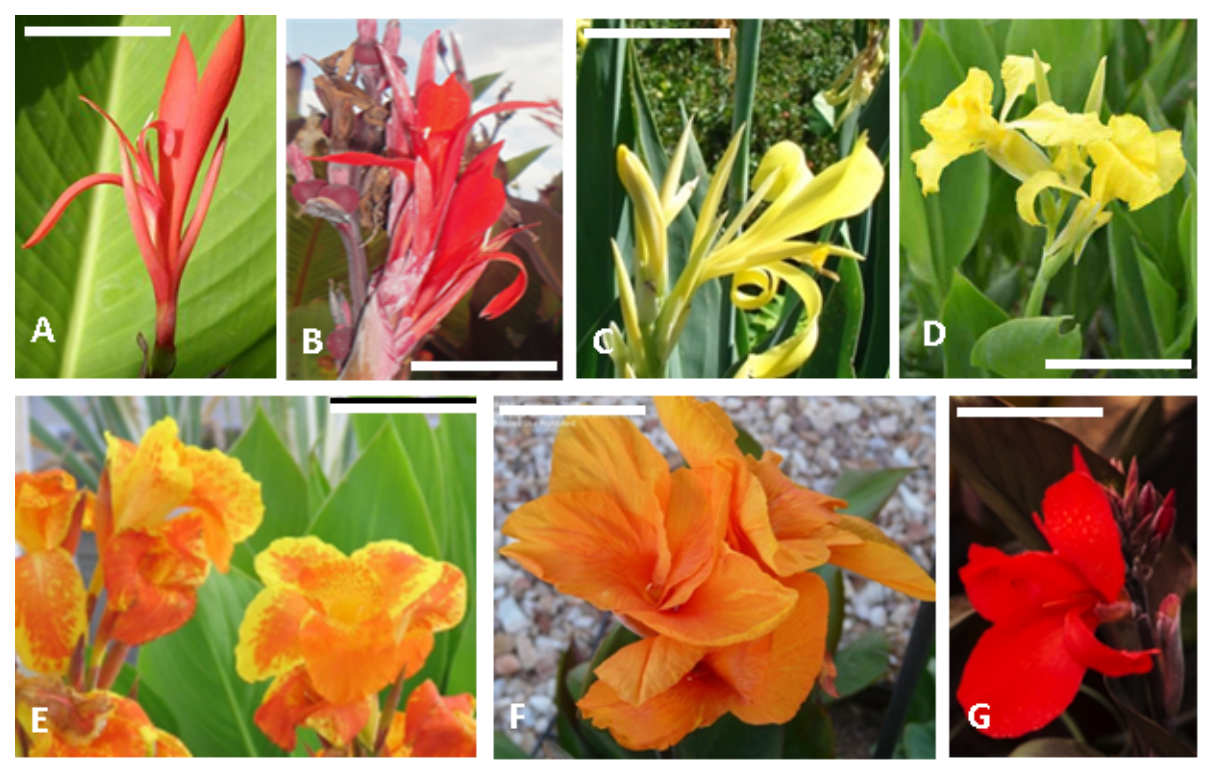

Fig. 1. Flores de especies parentales e híbridos de Canna. A: C. indica; B: C. warscewiczii; C: C. glauca; D: C. flaccida; E: C x generalis "King Humbert"; F: C. x generalis "Wyoming “; G: C. x generalis "Black Knight”. Escala= A: 3 cm; B: 2 cm; C: $6 \mathrm{~cm}$; D: $5 \mathrm{~cm} ; 7 \mathrm{~cm}$ en E- F; $5 \mathrm{~cm}$ en G. 
472 e/ 27 y 28, Ciciarelli, 110, 10-12-2014 (LP).

Canna x generalis "Black Knight”. ARGENTINA. Prov. Buenos Aires. Dpto. La Plata. City Bell. Calle 471 y 23, Ciciarelli,120, 10-12-2014 (LP).

Canna warscewiczii. ARGENTINA. Prov. Buenos Aires. Dpto. La Plata. City Bell. Calle 476 y Cno. Gral. Belgrano, 130, 10-12-2014 (LP).

\section{Resultados}

Los granos de polen son esferoidales, equinados y omniaberturados. El tamaño promedio de los granos en las especies silvestres es variable siendo C. warscewiczii la que posee menor tamaño de 33 a $38 \mu \mathrm{m}$. En las otras especies silvestres el tamaño es algo mayor: de 76 a $80 \mu \mathrm{m}$ en C. glauca y de 60 a $65 \mu \mathrm{m}$ en $C$. indica. En los cultivares los granos de polen presentan diferentes tamaños observándose tres tamaños diferentes en una misma muestra. Los granos de polen enteros y regulares son escasos y llegan a medir hasta $100 \mu \mathrm{m}$, los de tamaño intermedio se observan esferoidales o variablemente semiesferoidales, colapsados y oscilan entre los $60 \mathrm{y}$ $80 \mu \mathrm{m}$. En C. $x$ generalis "Black Knight" miden 58 (70) $100 \mu \mathrm{m}$, en C. $x$ generalis "King Humbert", 64 (76) $100 \mu \mathrm{m}$ y en C. $x$ generalis "Wyoming" 60 (72) $100 \mu \mathrm{m}$. Los valores intermedios se acercan a los registrados en C. glauca.

La exina siempre presenta espinas, sin embargo se observan diferentes tipos de microornamentación sobre la superficie de los granos; en las especies silvestres es microrugulada o microrugada, y las espinas son generalmente de tamaño homogéneo, cónicas, de ápice agudo o mamiformes, lisas con base ornamentada o granular, solitarias y equidistantes. En los híbridos los granos de polen son equinados o verrucosos y presentan una microornamentación casi lisa o microrugada sobre la superficie de la esporodermis. Las espinas o verrugas son siempre heterométricas: solitarias o más comúnmente próximas, formando grupos de 2-3 hasta 5 elementos (Cuadro 1).

\section{Canna glauca L. (Fig. 2 A-D)}

Granos de polen esferoidales, de (66) $76(80) \mu \mathrm{m}$, omniaberturados, equinados. Espinas uniformes,

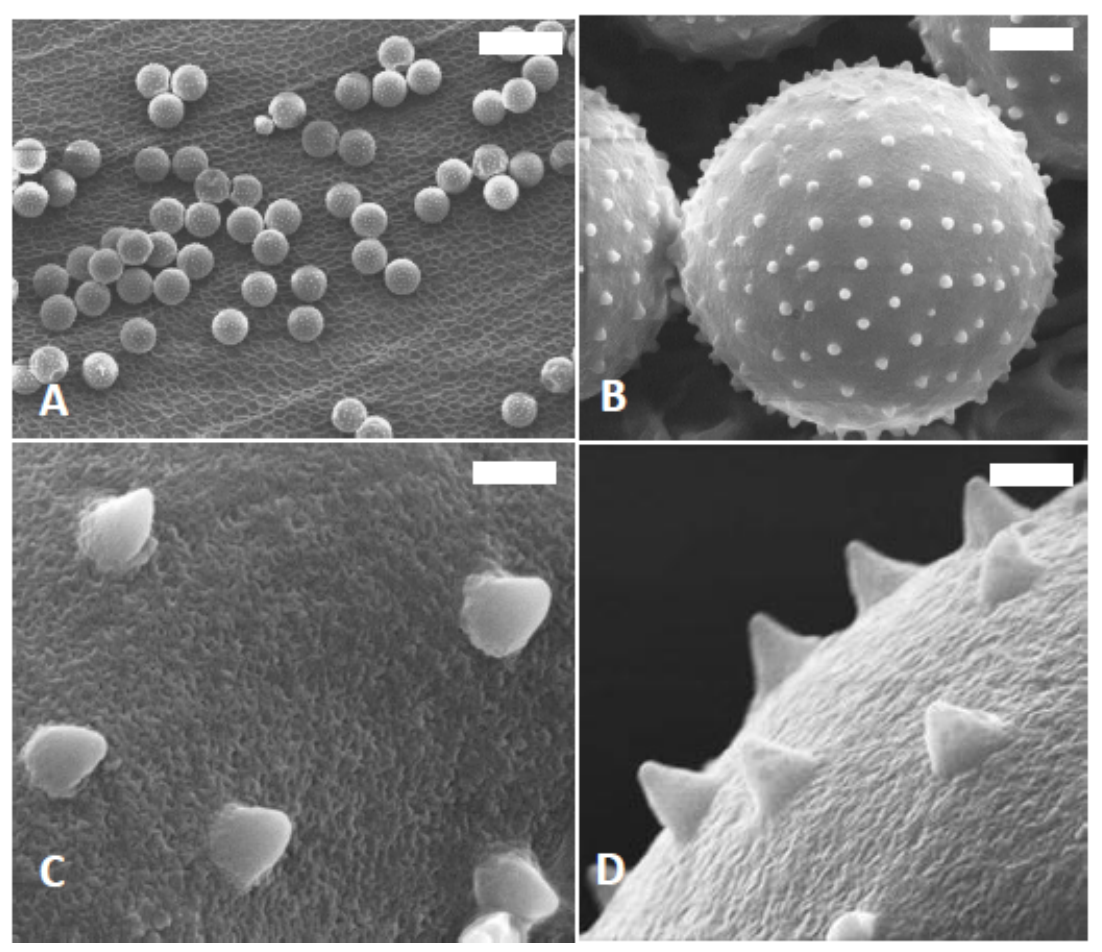

Fig. 2. Granos de polen de C. glauca. A: varios granos en vista general. B: grano aislado. C-D: disposición y distribución de las espinas. Escala= A, 136,8 $\mu \mathrm{m}$; B, 16,7 $\mu \mathrm{m} ; \mathrm{C}, \mathrm{D}, 2,25 \mu \mathrm{m}$. 


\section{M. Ciciarelli y L. M. Passarelli - Palinología y viabilidad en Canna e híbridos relacionados}

cónicas, muy claras y brillantes, con ápice redondeado, $3 \times 2,5 \mu \mathrm{m}$; densidad 8-10 espinas/ campo. Exina gris oscuro extendida hasta la base de las espinas. Superficie de las espinas lisa, con la base ornamentada. Microornamentación microrugada o micro-reticulada.

\section{Canna indica L. (Fig. 3 A-C-E)}

Granos de polen esferoidales, de (40) 60 (63) $\mu \mathrm{m}$, omniaberturados, equinados. Espinas uniformes, cónicas, claras, con ápice agudo, de 3,5 × $3 \mu \mathrm{m}$; densidad 9-13 espinas/campo. Exina gris extendida hasta la base de las espinas, éstas más claras. Superficie de las espinas lisa, con la base ornamentada. Microornamentación microrugada a micro-reticulada.
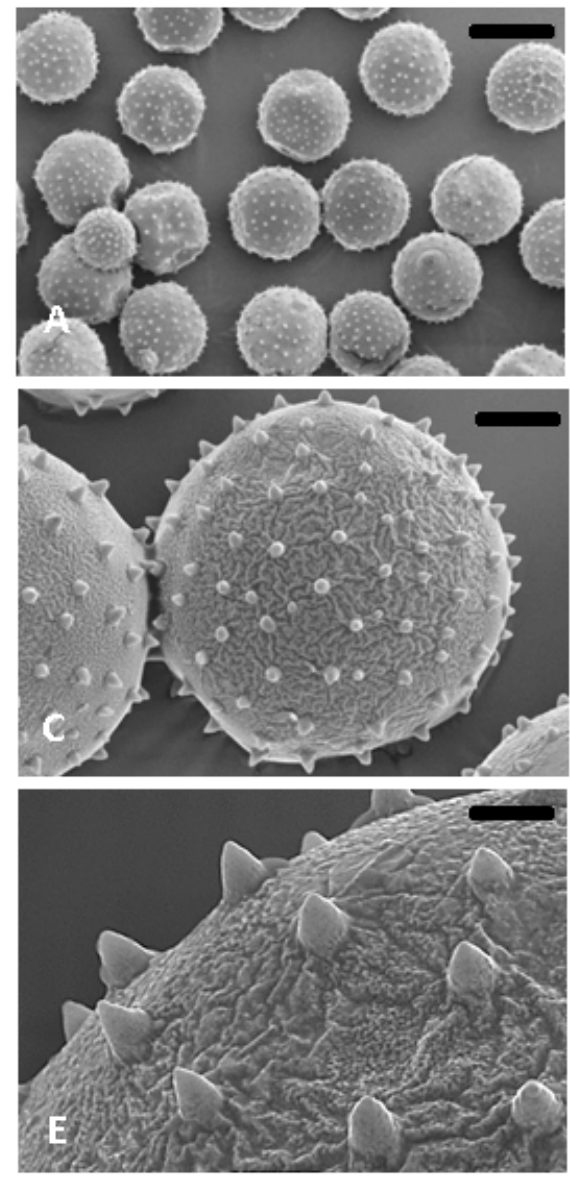

Canna warscewiczii A. Dietr. (Fig. 4 A-C)

Granos de polen esferoidales, de 30 (33) $38 \mu \mathrm{m}$ omniaberturados, equinados. Espinas uniformes mamiformes, de 2, 2 × $2 \mu \mathrm{m}$, densidad 13-19 espinas/ campo. Exina gris y espinas más claras. Superficie de las espinas lisa con la base ornamentada. Exina microrugulada a subreticulada.

\section{Canna $x$ generalis Black Knight (Fig. 3 B-D-F)}

Granos de polen esferoidales o semiesferoidales de 58 (70) $100 \mu \mathrm{m}$, omniaberturados, equinados. Espinas heterométricas, verrucosas o mamiformes solitarias o en grupos de hasta 5 unidades, lisas, de base ornamentada con microgránulos; de 2 × 3 $\mu \mathrm{m}$. Densidad 40 (45) 50 espinas por campo. Exina microrugada, gris en la base, espinas más claras.
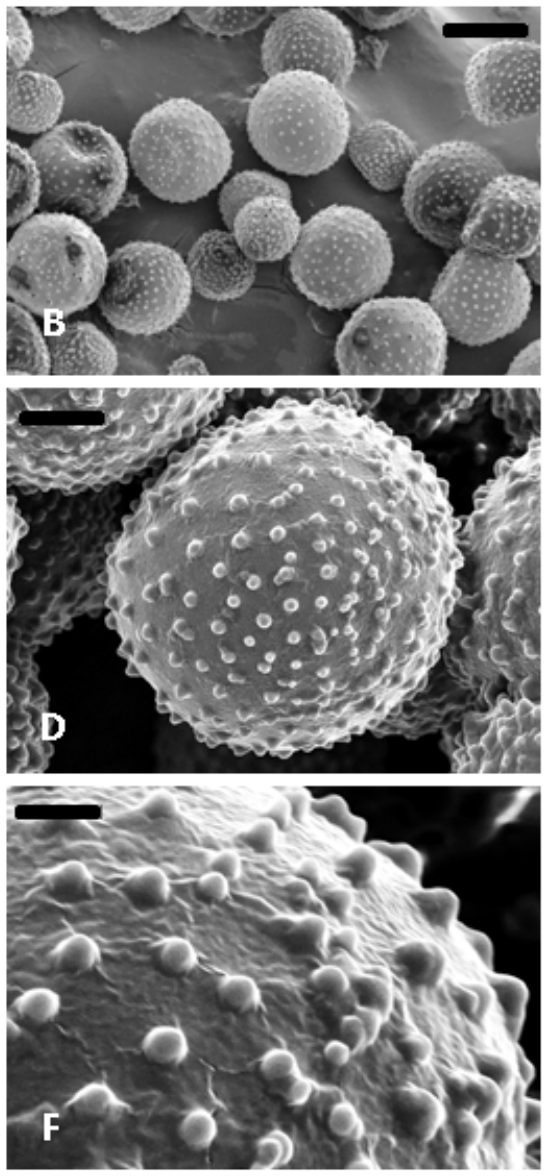

Fig. 3. Granos de polen de C. indica y C. x generalis "Black Knight". A, C, E, C. indica. B, D, F, C x generalis. A, B, varios granos en vista general. C, D: granos aislados. E, F: disposición, distribución de las espinas. D: detalle de la espina. Escala= A- B, $54 \mu \mathrm{m} ; \mathrm{C}, 13,5 \mu \mathrm{m}$; D, 16,6 $\mu \mathrm{m}$; E-F, 5,3 $\mu \mathrm{m}$. 

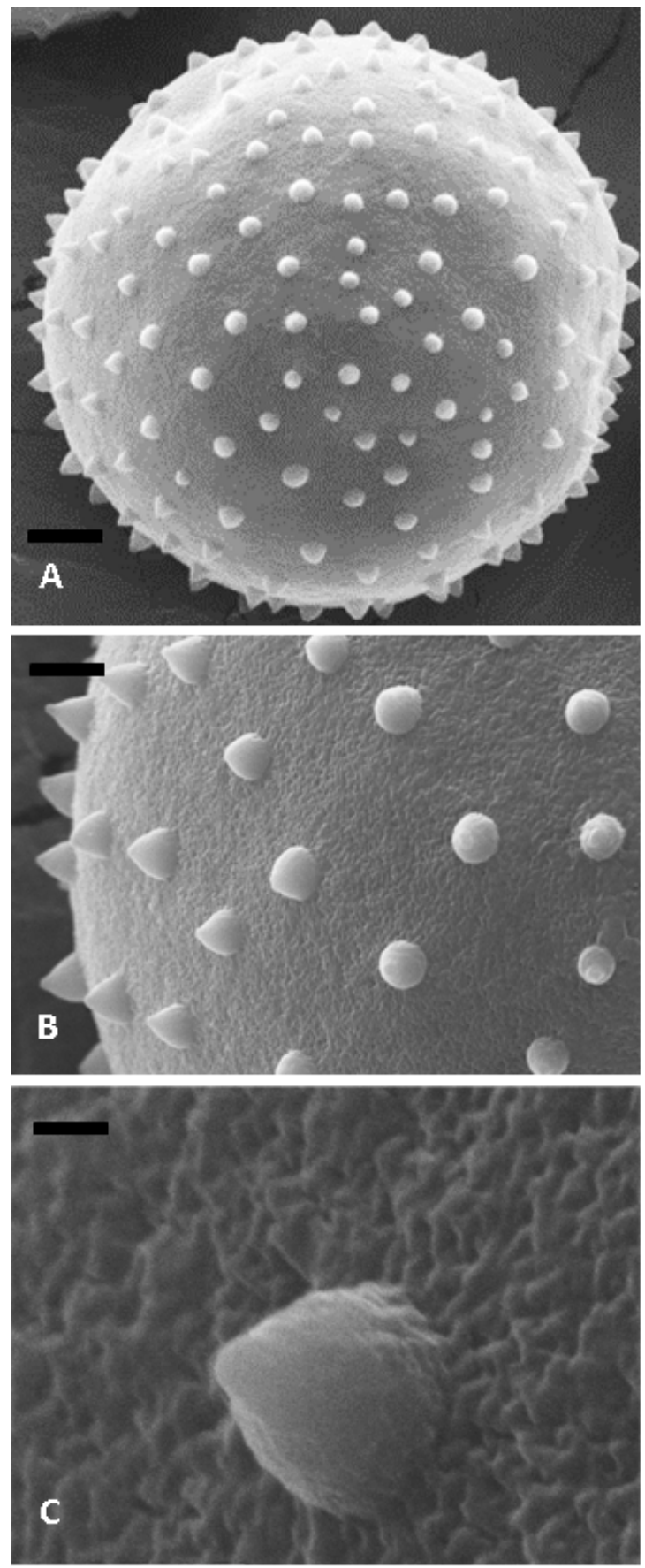

Fig. 4. Granos de polen de C. warscewiczii. A: Granos aislados, esferoidales; B. Disposición y distribución uniforme de las espinas; $\mathbf{C}$, detalle de las espinas y de la superficie de la pared. Escala= A, $4,5 \mu \mathrm{m}$; B, 3,5 $\mu \mathrm{m} ; \mathrm{C}, 0,7 \mu \mathrm{m}$.
Canna $x$ generalis King Humbert (Fig. 5 A-D)

Granos de polen esferoidales y semiesferoidales de 64 (76) $100 \mu \mathrm{m}$, omniaberturados, equinados. Espinas heterométricas verrucosas o mamiformes, de a 2-3, de 2 × 2,4 $\mu \mathrm{m}$, densidad 13-37 espinas/ campo. Exina gris claro, lisa en el ápice de los procesos y con la base ornamentada. Exina microgranular.

\section{Canna $x$ generalis Wyoming (Fig. 6 A-D)}

Granos de polen esferoidales y semiesferoidales de 60 (72) $100 \mu \mathrm{m}$. omniaberturados, equinados. Espinas heterométricas, cónicas con ápice agudo o curvado o mamiformes, de 3,7 × $3 \mu \mathrm{m}$, densidad de 10-22 espinas /campo. Exina en la base gris y espinas más claras. Microornamentación casi lisa con microgránulos.

\section{Discusión}

De acuerdo con Khoshoo \& Mukherjee (1970a, b) la domesticación artificial del género Canna ocurrió en Europa a partir de cinco especies parentales C. glauca, C. indica, C. iridiflora, C. flaccida y $C$. warscewiczii y dio como resultado un elevado número de híbridos. Estas prácticas llevaron 44 años, lapso en el cuál se forzó la potencialidad evolutiva del género y la comprensión de los mecanismos que tuvieron lugar. Las especies parentales presentan una porción de infertilidad debido a la segregación y recombinación genética propia de cada taxón y a una desarmonía debido a la inviabilidad genética producida por la presencia de anillos, cadenas, reordenamientos crípticos y falta de homología estructural a nivel cromosómico (Khoshoo \& Mukherjee, 1970e). Según Mukherjee et al. (1970a) la hibridación interespecífica y la mutación génica han permitido la amplia recombinación entre especies en su hábitat natural y los mutantes recesivos ocultos en el genoma de las especies silvestres se pudieron liberar y expresar en los fenotipos de los híbridos resultantes. La mutación génica es de importancia fundamental para la diferenciación morfológica, fisiológica y genética de las especies. (Mukherjee et al. 1970 a). Estos autores reportan mutaciones génicas somáticas y espontáneas en Canna, observables en la variegación foliar, cambios de color en flores y frutos y cambios de forma en 

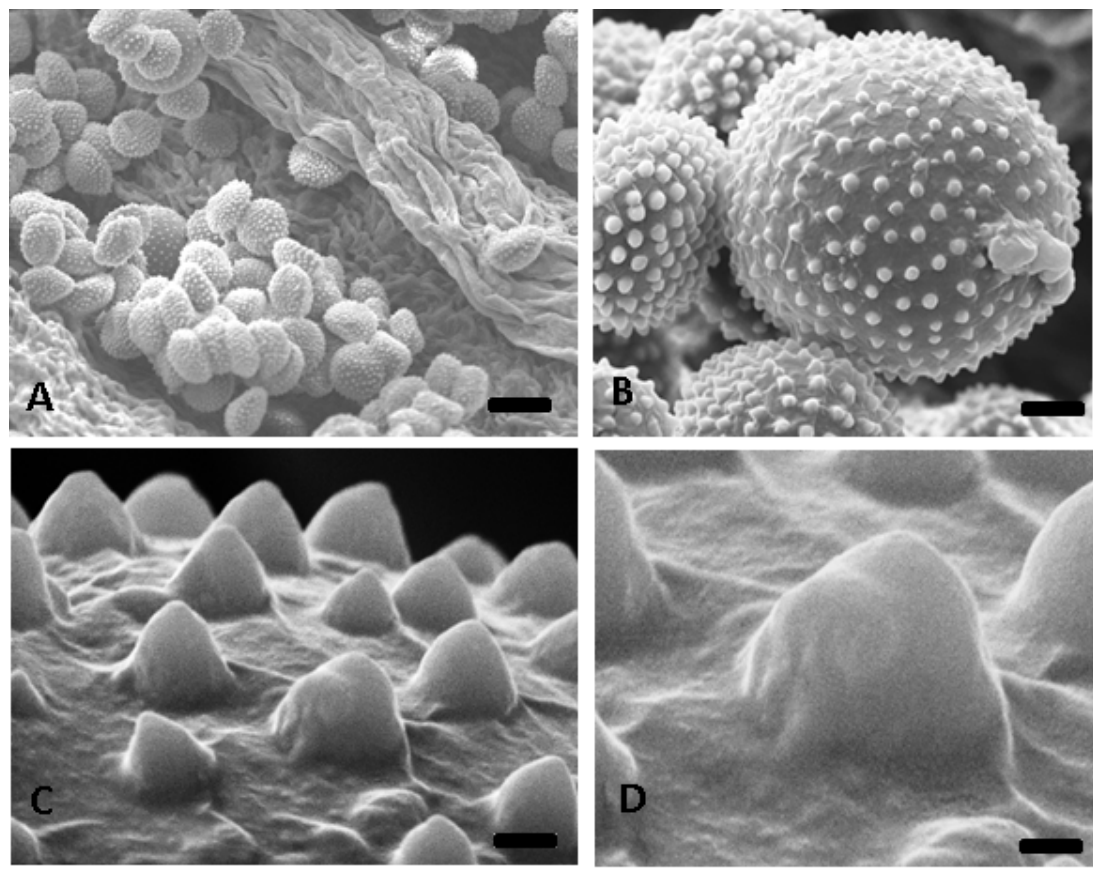

Fig. 5. Granos de polen de C. $x$ generalis "King Humbert". A: vista general, se observan granos de polen más pequeños y escasos granos de mayor tamaño; $\mathbf{B}$ : granos aislados; $\mathbf{C}$ : Disposición y distribución uniforme de las espinas; D: detalle de las espinas. Escala $=55 \mu \mathrm{m}$ en $A ; 12,3 \mu \mathrm{m}$ en $\mathrm{B} ; 1 \mu \mathrm{m}$ en $\mathrm{C} ; 0,5 \mu \mathrm{m}$ en D.
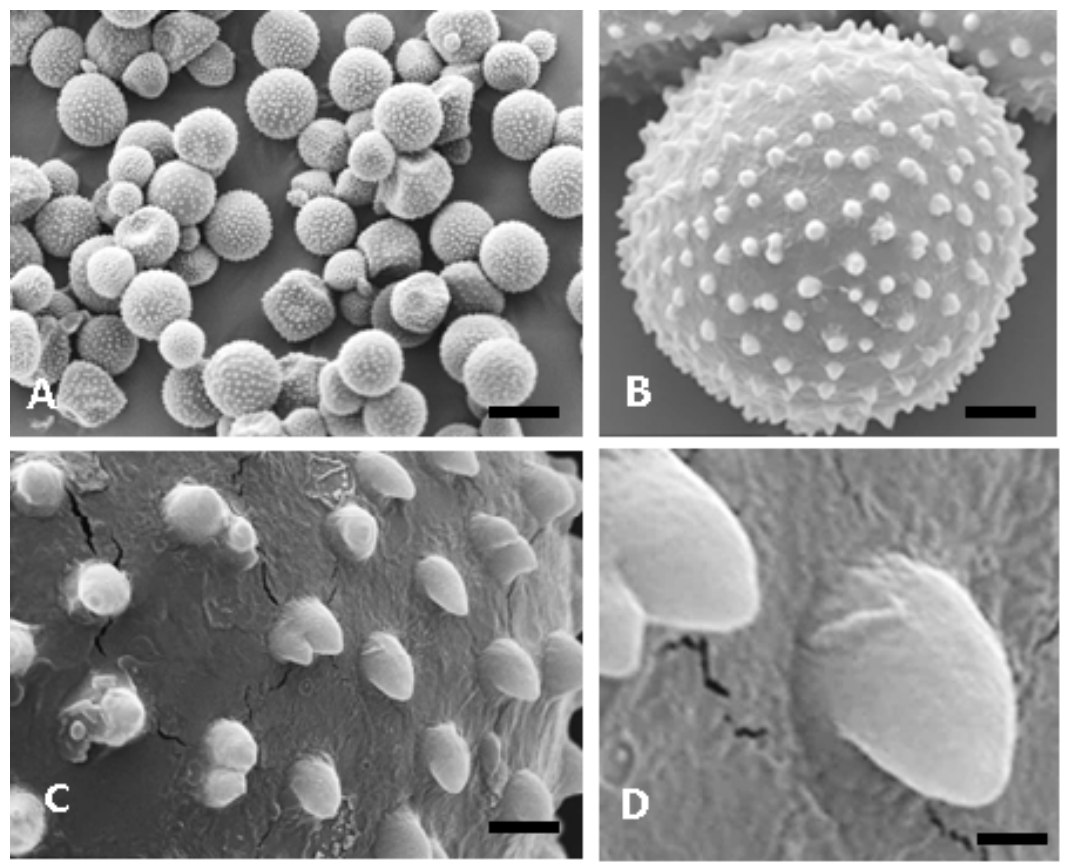

Fig. 6. Granos de polen de C. x generalis "Wyoming". A: vista general. Nóte las diferencias de tamaño de los granos; B: grano de polen esferoidal, C: Disposición y distribución de las espinas, se observan los procesos unidos de a pares; $\mathbf{D}$ : Detalle de las espinas. Escala $=64 \mu \mathrm{m}$ en $A ; 13 \mu \mathrm{m}$ en $B, 4,3 \mu \mathrm{m}$ en $C ; 1,3 \mu \mathrm{m}$ en D. 
piezas florales (Mukherjee \& Khoshoo, 1970a). La reproducción vegetativa es habitual en el género y como consecuencia de la misma se ha ido fijando la variabilidad útil resultado de la hibridación interespecífica y la recombinación de cada taxón, pero, al mismo tiempo se fueron acumulando genes letales, causantes de esterilidad. (Mukherjee \& Khoshoo, 1970a, b). En este sentido algunos de los híbridos son plantas diploides portadoras de semillas viables, mientras que otros son diploides o triploides productores de semillas estériles por degeneración del embrión. (Tokugawa et al. 1924; Khoshoo \& Mukherjee, 1970).

Las observaciones y los resultados obtenidos aquí concuerdan con los de la bibliografía citada. De acuerdo a nuestros registros $C$. glauca y $C$. indica presentan aproximadamente un $96 \%$ de viabilidad del polen, mientras que $C$. warscewiczii alcanza un $82 \%$. (Tabla 1). Estos valores se corresponden con una alta producción de semillas por cápsula en las tres especies parentales. Estos datos aportan además a la posibilidad de reconsiderar a $C$. warscewiczii como especie parental (Khoshoo \& Mukherjee, 1970) y no sólo ser tratada como sinónimo o subespecie de $C$. indica de acuerdo a otros autores (Maas \& Van de Kamer, 2008; Tanaka, 2001). Como ya se mencionó la creciente infertilidad de los híbridos se atribuye al aumento del número de cruzas. (Khoshoo \& Mukherjee, 1970). En ese sentido aquí se registró que si bien los tres híbridos carecen de óvulos normales todos producen frutos pequeños y carentes de semillas. En cuanto a los porcentajes de viabilidad del polen, en los híbridos se han registrado valores bajos a intermedios en relación a los observados en las especies parentales. El cultivar Cx generalis "Black Knight" del grupo antes denominado " $C x$ orchioides". Este cultivar registró el porcentaje más bajo del grupo con una viabilidad del $4 \%$.

La morfología de los granos de polen de Canna es un rasgo diagnóstico en taxones cultivados y silvestres (Nair 1960, Segeren y Maas 1971). Estudios palinológicos realizados previamente (Tanaka 2001, Ciciarelli 2007, Ciciarelli \& Rolleri 2008, Ciciarelli et al. 2010a, 2010b, Ciciarelli, 2014, 2015) demuestran que existen variaciones a nivel del tamaño de los granos, la microornamentación de la pared y de los procesos, espinas o gemas, siendo específicos en taxones silvestres. El tamaño promedio de los granos de polen en las especies silvestres es variable siendo $C$. warscewiczii la que posee menor tamaño $(33-38 \mu \mathrm{m})$, en las otras especies silvestres el tamaño es mayor: de 76-80 $\mu \mathrm{m}$ en $C$. glauca y de 60-65 $\mu \mathrm{m}$ en $C$. indica. Los granos de polen de los cultivares presentan hasta tres tamaños diferentes en una misma muestra. Los granos de polen enteros y regulares son escasos y llegan a medir hasta $100 \mathrm{~m}$, los de tamaño intermedio son esferoidales o variablemente semiesferoidales y colapsados. El tamaño oscila entre los 60-80 m.

Aunque los datos de densidad de las espinas aquí registrados son similares a los obtenidos por Tanaka (2001) se analizan otros rasgos de importancia diagnóstica como el tamaño, forma, ápice de los procesos y variaciones en la densidad y distribución de los mismos. En las especies silvestres las espinas son de tamaño uniforme, isométricas y se disponen según un patrón helicoidal sobre la superficie del grano. Estas pueden ser cónicas de ápice redondeado (C. glauca) o mamiformes (C. warscewiczii) o bien de ápice agudo $(C$. indica). En los cultivares son

Tabla 1. Viabilidad del polen y producción de semillas.

\begin{tabular}{|ccc|}
\hline Especies parentales /híbridos & Viabilidad del polen ( \%) & No semillas/ cápsula $^{\text {Canna glauca }}$ \\
Canna indica & 95.9 & 5 a 10 \\
Canna warscewiczii & 96.5 & 15 a 20 \\
Canna $x$ generalis Wyoming & 82 & 5 a 10 \\
Canna $x$ generalis King Humbert & 49 & 0 \\
Canna $x$ generalis Black Knight & 24 & 0 \\
\hline
\end{tabular}




\section{M. Ciciarelli y L. M. Passarelli - Palinología y viabilidad en Canna e híbridos relacionados}

siempre heterométricas, en $C . x$ generalis "Black knight" son verrucosas, mamiformes, solitarias o en grupos de 2-5; o en grupos de 2-3, en $C$. x generalis "King Humbert"; o bien cónicas, de ápice agudo o curvado, mamiformes, solitarias o en grupos de 2 en C. x generalis "Wyoming". (Tabla 2)

En C. glauca y $C$. indica la pared es oscura y en $C$. warscewiczii la pared es gris mientras que las espinas son claras en las tres especies. En $C$. $x$ generalis Wyoming y en $C$. $x$ generalis "Black Knight" la pared es gris y las espinas son claras. En C. $x$ generalis "King Humbert" la pared y las espinas tienen igual valor tonal pero en $C . \mathrm{x}$ generalis Wyoming y en $C$. $\mathrm{x}$ generalis "Black Knight" la pared es gris y las espinas son claras.

Las espinas son cónicas y de ápice agudo de 3-3,7 $\mu \mathrm{m}$ de long. y de $2,5-3 \mu \mathrm{m}$ de ancho en $C$. glauca, C. indica y en C. x generalis "Wyoming". Las espinas son verrucosas a mamiformes y de menor tamaño: entre 2-2,2 $\mu \mathrm{m}$ de long. y 2,4-3 $\mu \mathrm{m}$ de ancho en C. $x$ generalis "King Humbert", C. warscewiczii y C. x generalis "Black Knight". En las especies parentales la densidad de las espinas es menor que en los cultivares, así en $C$. glauca es de 9-10, en $C$. indica es de 11-13 y en $C$. warscewiczii de 16-19. En los cultivares la densidad de las espinas es de 23-37 en C. $x$ generalis "King Humbert", 16-22 en C. x generalis "Wyoming" y de 45-50 en C. $x$ generalis "Black Knight".

La superficie del esporodermo es microrrugulada subreticulada en $C$. glauca y $C$. warscewiczii y corrugada en $C$. indica. En C. $x$ generalis "King Humbert" es microgranular, lisa con microgránulos en $C . x$ generalis "Wyoming" y microrrugada

Tabla 2. Caracteres palinológicos

\begin{tabular}{|c|c|c|c|c|c|c|c|}
\hline Taxones & $\begin{array}{l}\text { Tamaño } \\
\text { de los } \\
\text { granos }\end{array}$ & $\begin{array}{l}\text { Tamaño } \\
\text { de las } \\
\text { espinas, I } \\
x \text { a basal, } \\
\text { en um }\end{array}$ & $\begin{array}{l}\text { Densidad } \\
\text { de espinas } \\
\text { por campo } \\
\text { de } 400 \text { um }^{2}\end{array}$ & $\begin{array}{c}\text { Forma de las } \\
\text { espinas }\end{array}$ & $\begin{array}{l}\text { Superficie del } \\
\text { esporodermo }\end{array}$ & $\begin{array}{l}\text { Superficie de } \\
\text { las espinas }\end{array}$ & $\begin{array}{l}\text { Tono y } \\
\text { valor tonal } \\
\text { de pared y } \\
\text { espinas }\end{array}$ \\
\hline C. glauca & 66 (76) 80 & $3 \times 2,5$ & 8 (9) 10 & $\begin{array}{l}\text { Isométricas } \\
\text { cónicas, ápice } \\
\text { redondeado }\end{array}$ & $\begin{array}{l}\text { Microrrugulada } \\
\text { sub reticulada }\end{array}$ & $\begin{array}{c}\text { Lisa, con } \\
\text { la base } \\
\text { ornamentada }\end{array}$ & $\begin{array}{c}\text { Pared oscura, } \\
\text { espinas } \\
\text { muy claras }\end{array}$ \\
\hline C. indica & $40(60) 63$ & $3,5 \times 3$ & 9 (11) 13 & $\begin{array}{l}\text { Isométricas } \\
\text { cónicas, ápice } \\
\text { agudo }\end{array}$ & Corrugada & $\begin{array}{c}\text { Lisa, con } \\
\text { la base } \\
\text { ornamentada }\end{array}$ & $\begin{array}{c}\text { Pared oscura, } \\
\text { espinas } \\
\text { muy claras }\end{array}$ \\
\hline $\begin{array}{c}\text { C. } \\
\text { warscewiczii }\end{array}$ & 30 (33) 38 & $2,2 \times 2$ & 13 (16) 19 & $\begin{array}{l}\text { Isométricas } \\
\text { mamiformes }\end{array}$ & $\begin{array}{l}\text { Microrrugulada } \\
\text { sub reticulada }\end{array}$ & $\begin{array}{c}\text { Lisa, con } \\
\text { la base } \\
\text { ornamentada }\end{array}$ & $\begin{array}{l}\text { Pared gris, } \\
\text { espinas } \\
\text { más claras }\end{array}$ \\
\hline $\begin{array}{c}C x \\
\text { generalis } \\
\text { "King } \\
\text { Humbert" * }\end{array}$ & $\begin{array}{c}64(76) \\
100\end{array}$ & $2 \times 2,4$ & 13 (23) 37 & $\begin{array}{l}\text { Heterométricas } \\
\text { verrucosas o, } \\
\text { mamiformes, } \\
\text { solitarias o en } \\
\text { grupos de } 2-3\end{array}$ & Microgranular & $\begin{array}{l}\text { Lisa en el } \\
\text { ápice con } \\
\text { la base } \\
\text { ornamentada }\end{array}$ & $\begin{array}{c}\text { Pared y } \\
\text { espinas de } \\
\text { igual valor }\end{array}$ \\
\hline $\begin{array}{c}C x \\
\text { generalis } \\
\text { "Wyoming" } \\
* *\end{array}$ & $\begin{array}{c}60(72) \\
100\end{array}$ & $3,7 \times 3$ & 10 (16) 22 & $\begin{array}{l}\text { Heterométricas } \\
\text { cónicas, ápice } \\
\text { agudo o curvado, } \\
\text { o mamiformes, } \\
\text { solitarias o en } \\
\text { grupos de } 2\end{array}$ & $\begin{array}{l}\text { Lisa con } \\
\text { microgránulos }\end{array}$ & $\begin{array}{l}\text { Lisa con } \\
\text { microgránulos, } \\
\text { abundante } \\
\text { pollenkit }\end{array}$ & $\begin{array}{l}\text { Pared gris, } \\
\text { espinas } \\
\text { muy claras }\end{array}$ \\
\hline $\begin{array}{c}C x \\
\text { generalis } \\
\text { "Black } \\
\text { knight" *** }\end{array}$ & $\begin{array}{c}58(70) \\
100\end{array}$ & $2 \times 3$ & 40 (45) 50 & $\begin{array}{l}\text { Heterométricas } \\
\text { verrucosas o, } \\
\text { mamiformes, } \\
\text { solitarias o } \\
\text { en grupos } \\
\text { de hasta } 5\end{array}$ & $\begin{array}{l}\text { Microrrugada, } \\
\text { espinas lisas } \\
\text { con base } \\
\text { ornamentada }\end{array}$ & $\begin{array}{l}\text { Lisa con } \\
\text { microgránulos }\end{array}$ & $\begin{array}{l}\text { Pared gris, } \\
\text { espinas } \\
\text { más claras }\end{array}$ \\
\hline
\end{tabular}

Referencias: *flores amarillas moteadas de naranja, hojas verdes; **flores anaranjadas, hojas púrpuras; ***flores coloradas, hojas púrpuras. 
en $C . x$ generalis "Black Knight". La superficie de las espinas es lisa y granular en la base en $C$. glauca y $C$. indica y lisa con la base ornamentada en $C$. warscewiczii, mientras que en C. $x$ generalis "King Humbert" la superficie de las espinas es lisa en el ápice, con la base ornamentada y lisa con microgránulos en los restantes cultivares.

\section{Conclusiones}

Como resultado de la domesticación se observan diferencias en los siguientes caracteres diagnósticos: ornamentación de la superficie de la esporodermis, morfología, tamaño del grano, distribución, tamaño y densidad de las espinas; y en aspectos fisiológicos: viabilidad de los granos y producción de semillas viables o ausencia de las mismas.

La viabilidad del polen refleja claramente el éxito reproductivo de las especies, estos valores son esenciales en el momento de realizar cruzamientos e hibridaciones, los datos obtenidos aquí, resumidos en la tabla 1, con valores cercanos al $96 \%$ en especies parentales y muy bajos en los híbridos (4 $\%$ en $C$. $x$ generalis "Black Knight") se relacionan con la producción elevada de semillas en las especies parentales y con la ausencia completa o baja producción de semillas en los híbridos.

El conocimiento de la morfología polínica y la viabilidad del polen en el género Canna no solo aporta información acerca de la hibridación y evolución artificial bajo domesticación, sino que además es de utilidad en estudios taxonómicos ya que permite el reconocimiento de especies silvestres o naturalizadas de posibles híbridos naturales o artificiales del género.

\section{Agradecimientos}

Este trabajo fue realizado en el marco del Programa de Incentivos para Docentes Investigadores de la Universidad Nacional de La Plata (Argentina) y del PI 809.

\section{Bibliografía}

BAILEY, L. H. 1923. Various cultigens and transfers in nomenclature. Gentes, Herb. 1: 120.
BAILEY, L. H. 1930. Canna $x$ generalis. Hortus, 18. https://doi.org/10.1002/bjs.1800187007

BAILEY, L. H. 1951. Manual of cultivated plants. MacMillan Publishing Co. New York.

BRICKELL, C. D., C. ALEXANDER, J. J. CUBEY, J. C. DAVID, H. A. HOFFMAN, A.C. LESLIE, V. MALECOT, XIAOBAI JIN. (eds) 2009. International Code of Nomenclature for Cultivated Plants.

CICIARELLI, M. M. 2007. Canna ascendens Ciciarelli (Cannaceae) una nueva especie de la provincia de Buenos Aires y comentarios de otras especies argentinas de este género. Darwiniana 45: 188-200

CICIARELLI, M. M. 2014. Canna lineata Ciciarelli, una nueva especie para los humedales bonaerenses, Argentina. Bot. Complutensis 38:115-121. https://doi.org/10.5209/rev_BOCM.2014.v38.45780

CICIARELLI, M. M. 2015. Canna tandilensis Ciciarelli (Cannaceae-Zingiberales) una especie nueva para Argentina. Bot. Complutensis. 39: 87-96. https://doi.org/10.5209/rev_BOCM.2015.v39.49137

CICIARELLI, M. M., PASSARELLI, L.M. \& ROLLERI, C.H. 2010. Morfología del polen en especies de Canna L. (Cannaceae, Zingiberales) y su implicancia sistemática. Rev. Biol. Trop. 58: 63-59. https://doi.org/10.15517/rbt.v58i1.5194

CICIARELLI, M. M. \& ROLLERI, C.H. 2008. Morfología, taxonomía y caracterización de siete especies neotropicales del género Canna (CannaceaeZingiberales). Bot. Complutensis 32: 157-184.

CiCIARELli, M. M., ROLleri, C. H., M. C. GONZALEZ DUBOX. 2010b. Canna fuchsina (Cannaceae- Zingiberales), una especie nueva para la Argentina y sus relaciones con otras especies del género. Bot. Complutensis 34: 49-55.

ERDTMAN G. 1960. The Acetolysis Method - A Revised Description. Svensk Botanisk Tidskrift 54: 561-564.

KHOSHOO, T. N. \& I. MUKHERJEE. 1970. Geneticevolutionary studies on cultivated cannas. Origin and Evolution of Ornamental Taxa. Theoret. Appl. Genetics. 40: 204-217.

https://doi.org/10.1007/BF00285243

KHOSHOO, T. N. \& I.MUKHERJEE. 1970b. Geneticevolutionary studies on cultivated cannas. Pollination mechanism and breeding system. Proc. Indian. Natn. Sci. Acad. 36: 271-274.

KHOSHOO, T.N. \& I. MUKHERJEE. 1970c. Geneticevolutionary studies on cultivated cannas. Parallelism between induced and natural mutations. Rad. Botany 10:351-364. https://doi.org/10.1016/S0033-7560(70)80076-X 


\section{M. Ciciarelli y L. M. Passarelli - Palinología y viabilidad en Canna e híbridos relacionados}

KHOSHOO, T. N. \& I. MUKHERJEE. 1970d. Genetic-evolutionary studies on cultivated cannas. Intraspecific polyploidy in yielding Canna edulis. Genetica Iberica 67: 137-138.

MAAS-VAN DE KAMER, H. \& P. J. M. MAAS. 2008. The Cannaceae of the world. Blumea 53: 247- 318.

MUKHERJEE I. \& T. N. KHOSHOO, T. N. 1970a. Genetic evolutionary studies on cultivated cannas. Variation in phenotype. Proc. Indian. Natn. Sci. Acad. 36 B: 254:270.

MUKHERJEE I. \& T. N. KHOSHOO, T. N. 1970b. Genetic evolutionary studies on cultivated cannas. Taxonomic treatment horticultural classification. J. Bombay Nat. Hist. Soc. 67: 137-138.

NAIR, P. K. K. 1960. Pollen grains of cultivated plants. I: Canna. J. Indian Bot. Soc. 39: 373-381.

RODRIGUEZ-RIANO, T. \& A. DAFNI. 2000. A new procedure to asses pollen viability. Sex Plant Reprod. 12: 241- 244. https://doi.org/10.1007/s004970050008

SEGEREN, W. \& MAAS, P. J. M. 1971. The genus Canna in Northern South America. Acta Bot. Neerl. 20: 663- 680 . https://doi.org/10.1111/j.1438-8677.1971.tb00210.x

SHIVANNA K. R. JOHRI B. M. 1985. The Angiosperm pollen: Structure and Function. Wiley Eastern Lim. New Delhi, India.

TANAKA, N. 2001. Taxonomic revision of the family Cannaceae in the New World and Asia. Makinoa ser. 2: 31-3.

TOKUGAWA Y \& KUWADA Y. 1924. Cytol. stud. on some garden varieties of Canna. Jap. Journ. of Bot. Bd. 2: 152-170.

WODEHOUSE, R. P.1935. Pollen grains. Their structure, identification and significance in science and medicine. Mc. GrawHill. Nueva York. 
